globais. Para atingir os objectivos estratégicos de 2009-2013, propõe-se actuar a vários níveis:

- Fortalecer a base científica

- Concretizar a política de desenvolvimento

- Encorajar o desenvolvimento profissional e as redes

- Promover parcerias efectivas

- Aumentar a comunicação e reconhecimento

- Melhorar a tomada de decisões na governação e finanças

2. Informações diversas:

- A Química e o European Research Council (descrição dos programas de bolsas, possibilidades na área e dados sobre o sucesso)

- Os congressos da EuCheMS (2012, Praga; 2014, Istambul; 2016, Espanha). No congresso de Praga foram estabelecidos preços de $400 €$ (membros de sociedades da EuCheMS), $220 €$ (estudantes membros de sociedades da EuCheMS) e 600€ (não sócios)

- Colaborações com a Federação da Sociedades Químicas da Ásia (FACS), American Chemical Society (ACS), European Chemistry Thematic Network Association (ECTN - sucesso das acreditações Eurobachelor, Euromaster, Eurodoctor), FECCIA (Federação Europeia dos Empresários na Química e Indústria Química - o problema do envelhecimento da mão de obra), European Federation for Medicinal Chemistry (próxima conferência Lisboa, 2014), CE-
FIC (o projecto Europe 2020)

- Criação dum novo WP em Ciência e Ética (quem estiver interessado pode contactar a SPQ)

- Foram entregues os EuCheMS Awards aos recipientes de 2011 e foi anunciado que o Award relativo a 2012 tinha sido atribuído a José Empis, da Sociedade Portuguesa de Química, que entre muitas outras actividades foi um dinamizador do WP e da Divisão de Química Alimentar em Portugal e na EuCheMS, e foi o primeiro tesoureiro da EuCheMS. A SPQ congratula-se com esta decisão e felicita o Prof. José Empis

\section{Grupos de discussão}

Existe um período da AG destinado a discutir assuntos de interesse geral, sendo depois apresentadas as conclusões.

A - European Research Council (fui convidada para coordenar, com Michele Aresta, este grupo). O sucesso na área da química é semelhante (ou levemente maior) ao das outras $(\sim 15 \%)$, mas depende muito do país. Das duas áreas possíveis (PE4 Physical \& Analytical Chemical sciences; PE5 Materials \& Synthesis), foram submetidas 26 propostas por grupos portugueses em PE4 e 26 em PE5 (20012011) e nenhuma foi aprovada.

B - Horizons 2020. Foi publicado um texto (Chemistry-Developing solutions in a changing world) destinado a realçar o papel central da Química na resolução dos desafios que se põem neste mundo em mudança. O exemplar em papel distribuído encontra-se na sede da SPQ (foi anteriormente enviado por correio electrónico a todos os sócios). Neste grupo debateram-se estas questões - Roadmaps.

C - Core activities. Como definir produtos que sejam "vendáveis" e ajudem a diversificar fontes de financiamento?

D - Open Access journals. Este é um tópico muito importante. É um novo tipo de negócio na publicação de resultados científicos. No entanto, parte significativa das sociedades científicas sobrevive devido à publicação de revistas de reconhecida qualidade (a SPQ participa no consórcio ChemPubSoc Europe). Nas revistas Open Access quem paga é o autor e o acesso é grátis para os leitores. $O$ autor pode dispôr do artigo (página pessoal, por exemplo). Dada a dimensão que já alcança, as próprias sociedades estão a criar soluções alternativas (pagar uma quantia que dá o acesso livre a um dado artigo), embora sem grande expressão. Que acontecerá a longo prazo à qualidade das publicações? O financiamento da investigação vai ser usado directamente para pagar a publicação?

A AG admitiu escrever um texto chamando a atenção para estas preocupações.

\section{Maria José Calhorda}

(mjc@fc.ul.pt)

Vice-Presidente da SPQ

\title{
Prémio Nobel da Química 2011: atRibuído Pela descoberta dos QuaSe-CristalS
}

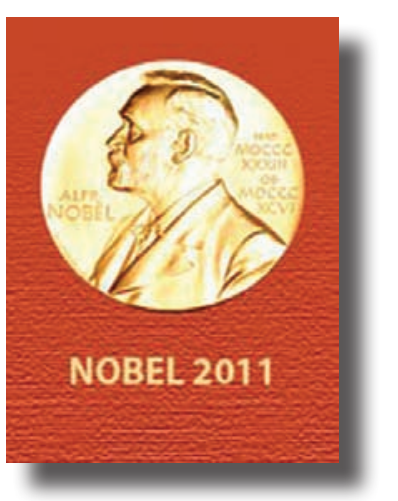

O Prémio Nobel da Química 2011 foi atribuído a Dan Shechtman (Technion - Israel Institute of Technology, Haifa, Israel), pela descoberta que os átomos nos quase-cristais (quasicristais) apresentam um padrão regular que nunca se repete. Nos quasecristais conseguimos encontrar o arranjo fascinante dos mosaicos Árabes reproduzido ao nível de átomos: padrões regulares que não se repetem!
Com esta descoberta, Dan Shechtman, nascido em 1941 em Tel Aviv, Israel, contrariou a ciência até então estabelecida, pois esta configuração era considerada impossível, e alterou de forma fundamental a maneira como os químicos entendem a matéria sólida.

Na manhã de 8 de Abril de 1982, apareceu no microscópio electrónico 
de Dan Shechtman uma imagem que contrariava as consideradas "leis da natureza". Em toda a matéria sólida, acreditava-se que os átomos eram acondicionados em cristais com padrões simétricos que se repetiam periodicamente, vezes sem fim. Para os cientistas, esta repetição era necessária para se obter um cristal. Até há altura, acreditava-se que podia haver simetria rotacional de 2, 3, 4 ou 6 eixos, mas alguns tipos de simetria com 5,7 ou mais eixos não eram viáveis (Figura 1).

A imagem de Shechtman mostrava contudo que os átomos naquele cristal dispunham-se com um padrão que não se repetia. Este padrão era considerado tão impossível quanto criar uma bola de futebol apenas com polígonos hexagonais, quando uma esfera necessita de polímeros quer com 6 , quer com 5 lados. O material sólido, obtido por síntese, e composto por alumínio e magnésio, assemelhava-se ao nível molecular a mosaicos árabes, uma vez que obedecem a regras matemáticas sem contudo repetirem padrões (Figuras 2 e 3 ).

A sua descoberta foi extremamente controversa, levando mesmo a um pedido para que Shechtman se retirasse do seu grupo de investigação. No entanto, a sua batalha eventualmente forçou os cientistas a reconsiderar a sua concepção sobre a própria natureza da matéria. Em 1992, depois da descoberta de Shechtman ser comprovada e reconhecida oficialmente, a União Internacional de Cristalografia alterou a definição do termo "cristal" para englobar também os quasecristais. Actualmente, esta definição não faz qualquer tentativa de definir directamente o conceito de cristal, fornecendo antes uma definição operativa baseada no padrão de difracção do material: "por cristal considera-se qualquer sólido que tenha um diagrama de difracção essencialmente discreto". Esta definição deixa espaço para estruturas ainda desconhecidas, num sinal de humildade face a descobertas futuras.

O feito conseguido por Dan Shechtman não foi apenas a descoberta dos quase-cristais, mas também a consciência da importância dos seus resul-
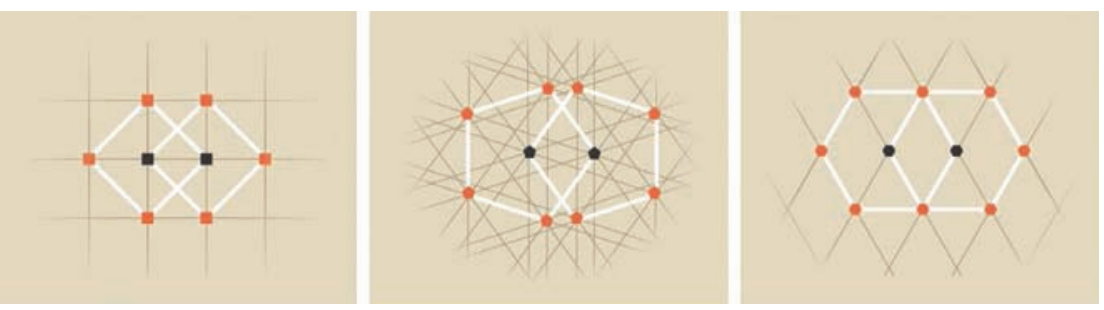

Figura 1 - Simetrias rotacionais de 4-eixos (esquerda) ou de 6-eixos (direita) geram novos eixos de rotação à mesma distância de separação, como no par original, logo, a sua repetição gera periodicidade. No caso de simetria de 5-eixos (centro), gera-se uma nova distância, mais curta, resultando em não-periodicidade

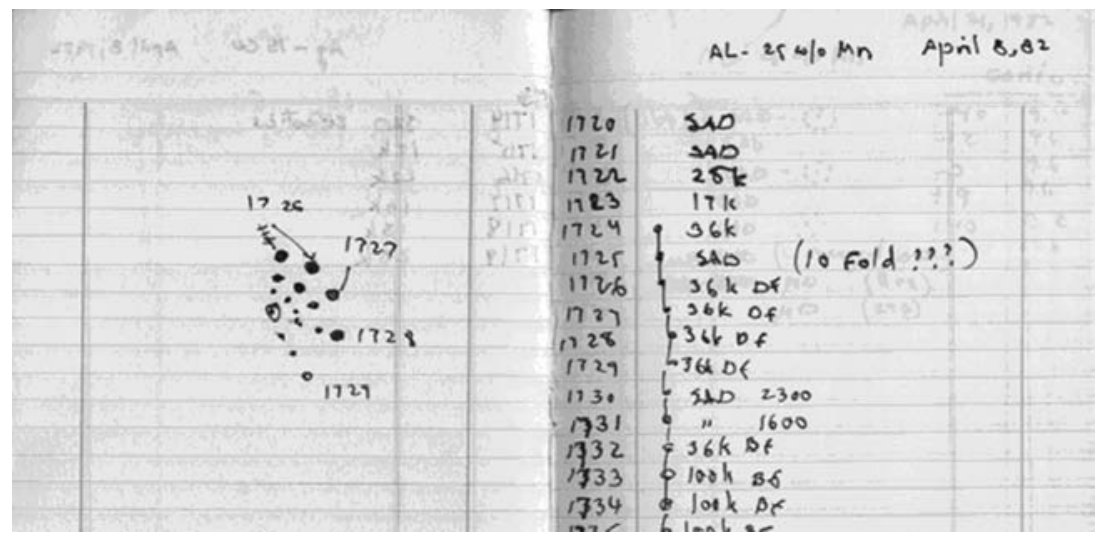

Figura 2 - Anotações de Dan Shechtman relativas à descoberta dos quase-cristais no dia 8 de Abril de 1982. Note-se a escrita de "10 Fold !!!" (www.quasi.iastate.edu/discovery.html)

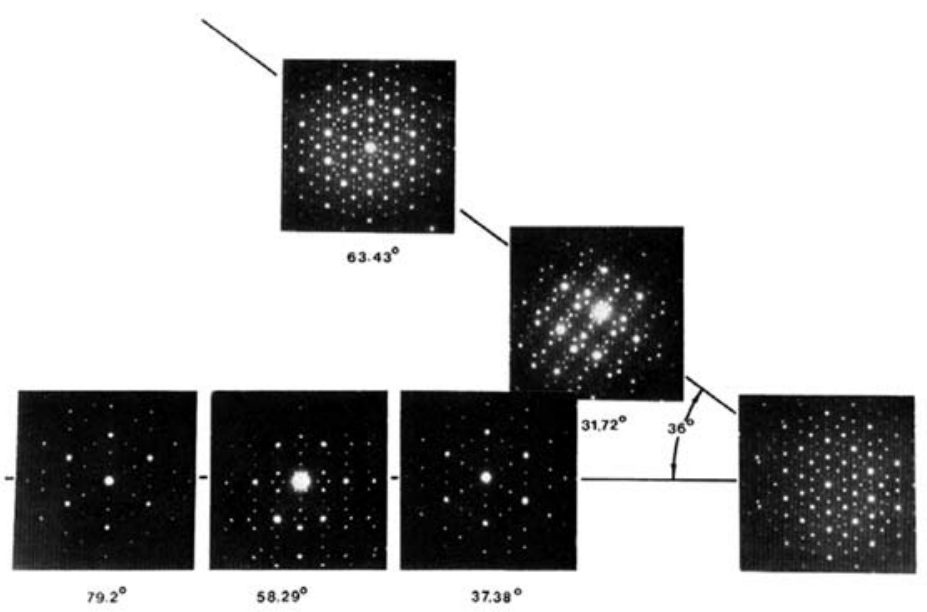

Figura 3 - Imagens originais visualizadas ao microscópio electrónico por Dan Shechtman

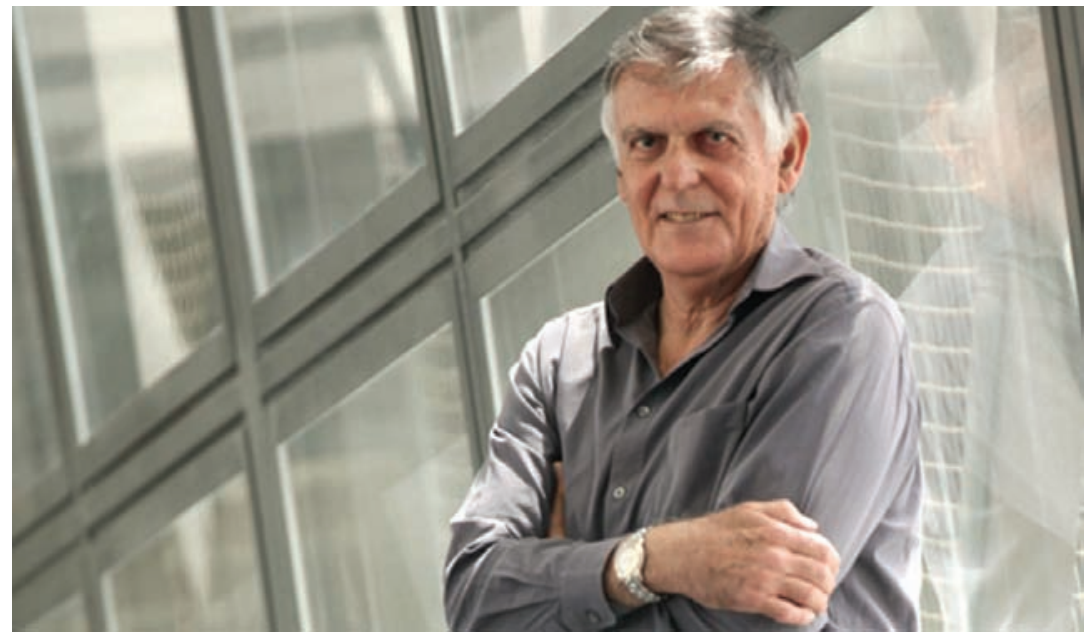

Professor Dan Shechtman no Technion - Israel Institute of Technology, Israel (Fonte: "Photo Gallery". Nobelprize.org. 7 Nov 2011) 
tados, bem como a sua determinação em comunicar os mesmos face ao cepticismo da comunidade científica. (Fonte: "The Nobel Prize in Chemistry
2011 - Press release" e "The Nobel Prize in Chemistry 2011 - Scientific background", Nobelprize.org, 7 Nov 2011, Real Academia Sueca de Ciências)
Joana Amaral

(bquimica@ipb.pt) www.spq.pt

Fernando Manuel Ramôa Cardoso Ribeiro

(FunchAL, 04/10/1945 - LISBOA, 29/08/2011)

Conheci o Ramôa em 1962, quando ambos ingressámos na Licenciatura em Engenharia Químico-Industrial na Universidade do Porto. Passados 6 anos, estávamos entre a meia dúzia de colegas que tinha completado o curso sem perder qualquer ano. As palavras que o nosso colega Rui Pinto Ihe dedicou para o livro do $5^{\circ}$ ano de curso descrevem bem o estudante Ramôa: "Sempre nas aulas atento/ Tirando seu apontamento/ Não deixando nada à toa/ o meu colega Ramôa/ vai fazendo suas cadeiras/ sem fazer quaisquer asneiras/ Nos estudos ele é "urso"/ E, sendo o benjamim do curso/ Auguro-Ihe grande sucesso/ No caminho do progresso." Desse tempo passado na Invicta ficou-lhe para sempre a paixão pelo Futebol Clube do Porto. Iniciámos então carreiras paralelas: o Ramôa entrou como assistente na Universidade de Coimbra, e eu fiquei na FEUP. Quando em 1975 regressei de Londres, onde me doutorei num

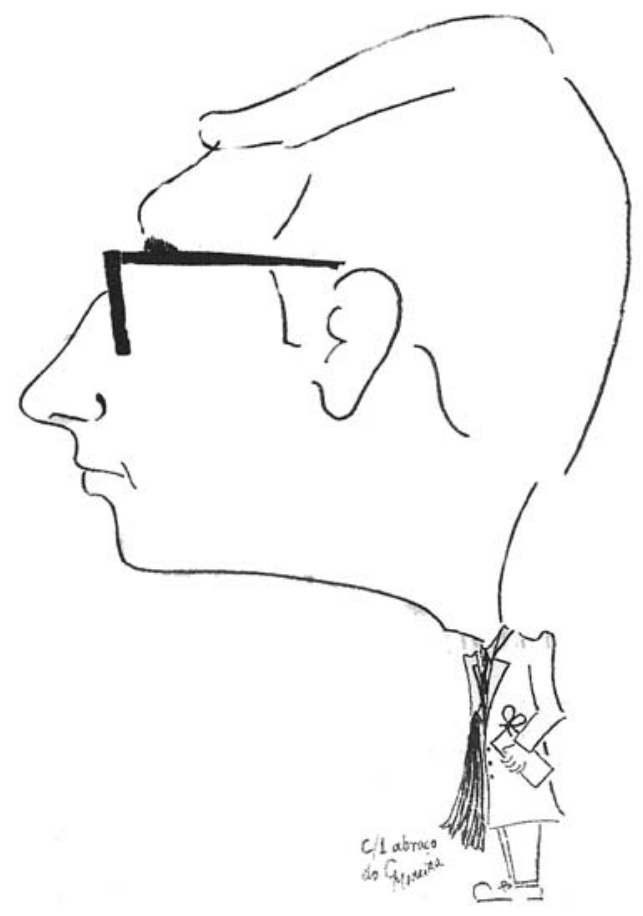

FRR em 1967 visto pelo colega Fernando Moreira tema de Catálise Heterogénea, vim encontrar o Ramôa no Instituto Superior Técnico, integrado num grupo de investigação da mesma área. Entretanto, ele tinha cumprido o serviço militar obrigatório, tendo sido destacado para o Instituto Hidrográfico da Marinha, uma posição muito pretendida pelos Engenheiros Químicos (pois assim se evitava a ida para a guerra colonial), mas que só estava ao alcance dos Licenciados com as melhores classificações. Ele também ambicionava fazer o Doutoramento no estrangeiro (na nossa área, e naquela altura, era impossível fazê-lo no País), mas o director do grupo não se mostrava muito entusiasmado com a ideia. Foi preciso apresentar-Ihe o facto consumado, nomeadamente um convite irrecusável do Instituto Francês do Petróleo (IFP), que o Ramôa conseguiu obter do Doutor Roger Montarnal durante o $5^{\circ}$ Simpósio Ibero-Americano de Catálise, que decorreu em Lisboa em 1976.

A sua tese de Doutoramento, realizada no IFP de 1977 a 1980 sob orientação do Professor Christian Marcilly, em colaboração com a Universidade de Poitiers, versou sobre a preparação e propriedades catalíticas da platina suportada em zeólitos. Este trabalho, em particular a técnica de permuta iónica com competição desenvolvida para preparar catalisadores metálicos suportados [cf. Revue de l'Institut Français du Pétrole, vol. XXXIV, 1979, 405-428], constitui um exemplo notável da aplicação de princípios científicos à preparação de catalisadores, que era então mais uma arte do que uma ciência. Em 22 de Março de 1980 obteve o Doutoramento pela
Universidade de Poitiers, sendo seu patrono o Professor Michel Guisnet, com o qual viria a manter uma estreita colaboração durante toda a vida. Quando regressou ao IST criou o seu próprio grupo de investigação sobre Catálise por Zeólitos, que rapidamente se transformou numa referência, não só a nível nacional, mas também a nível europeu, sobretudo devido às colaborações intensas que manteve com cientistas de renome, nomeadamente Michel Guisnet (Poitiers), Eric Derouane (Namur; Liverpool; Faro), Jacques Védrine (Liverpool; Paris) e Michel Che (Paris). Aliás, uma das características do seu grupo era que todos os seus colaboradores e doutorandos tinham necessariamente que desenvolver uma parte mais ou menos extensa do seu trabalho no estrangeiro (em particular no grupo de Michel Guisnet, na Universidade de Poitiers). Esta intensa e profícua colaboração, e o seu contributo para o desenvolvimento das relações bilaterais com as instituições científicas e Universidades da França, mereceram o reconhecimento do Governo Francês, que lhe atribui várias condecorações, entre as quais a Ordem de Chevalier de la Légion d'Honneur.

Tive oportunidade de acompanhar muito de perto toda a carreira académica do Ramôa após o Doutoramento, pois estive presente em quase todos os seus júris: Equiparação de Doutoramento (1980); Concurso para Professor Associado (1985); e Provas de Agregação, em que fui arguente (1988).

Em 1981 o Ramôa participou, creio que pela primeira vez, num Curso Avançado NATO (Advanced Study Institute on Catalyst Deactivation, Lagos, Algarve). Tendo apreciado o formato, e reconhecendo-Ihe o potencial para fomentar a internacionalização do seu grupo de investigação, logo 